University of Nebraska - Lincoln

DigitalCommons@University of Nebraska - Lincoln

Faculty Publications from the Center for Plant

Science Innovation

Plant Science Innovation, Center for

2008

\title{
Ultrastructural Alterations in Arabidopsis thaliana dj1c Null Mutant Cotyledons
}

Han Chen

University of Nebraska-Lincoln, hchen3@unl.edu

J. L. Frey

University of Nebraska-Lincoln

Tara Nazarenus

University of Nebraska-Lincoln, tnazarenus2@unl.edu

Christian Elowsky

University of Nebraska-Lincoln, celowsky@unl.edu

Julie M. Stone

University of Nebraska-Lincoln, jstone2@unl.edu

Follow this and additional works at: https://digitalcommons.unl.edu/plantscifacpub

Part of the Plant Sciences Commons

Chen, Han; Frey, J. L.; Nazarenus, Tara; Elowsky, Christian; and Stone, Julie M., "Ultrastructural Alterations in Arabidopsis thaliana dj1c Null Mutant Cotyledons" (2008). Faculty Publications from the Center for Plant Science Innovation. 35.

https://digitalcommons.unl.edu/plantscifacpub/35

This Article is brought to you for free and open access by the Plant Science Innovation, Center for at DigitalCommons@University of Nebraska - Lincoln. It has been accepted for inclusion in Faculty Publications from the Center for Plant Science Innovation by an authorized administrator of DigitalCommons@University of Nebraska Lincoln. 


\title{
Ultrastructural Alterations in Arabidopsis thaliana dj1c Null Mutant Cotyledons
}

\author{
H. Chen, ${ }^{*}$ J. L. Frey, ${ }^{* *}$ T. J. Nazarenus, ${ }^{* *}$ C. G. Elowsky, ${ }^{*}$ and J. M. Stone**
}

*Microscopy Core Facility, Center for Biotechnology, University of Nebraska-Lincoln, E119.5 Beadle Center, 1901 Vine Street, Lincoln, NE 68588

**Department of Biochemistry, Plant Science Initiative, Redox Biology Center, University of Nebraska-Lincoln, N230 Beadle Center, 1901 Vine Street, Lincoln, NE 68588

Increasing evidence suggests that deficits in mitochondrial function, oxidative and nitrosative stress, accumulation of aberrant or misfolded proteins, and ubiquitin-proteasome system dysfunction may represent the principal molecular pathways that commonly underlie the pathogenesis of neurodegenerative Parkinson's disease (PD). Mutations in human DJ-1 lead to early onset PD. The subcellular distribution of DJ-1 (PARK7) is primarily cytoplasmic with smaller quantities found associated with mitochondria. Postulated functions include roles in the oxidative stress response, either as a redox sensor protein that can prevent the aggregation of alpha-synuclein or as an antioxidant. Homologs of DJ-1 are found in all kingdoms of life [1]. To understand the functions of plant DJ-1 homologs we identified null mutants in the model plant Arabidopsis thaliana. One of the 3 Arabidopsis genes encoding DJ1 homologs (DJ1C) is essential for viability, and null knockout mutants are seedling lethal (Figure 1).

The cellular ultrastructures of $d j 1 c$ null mutant cotyledons were observed by transmission electron microscopy (TEM). For TEM, thin sections of cotyledon tissue were prepared and analyzed essentially as described with some modifications [2]. Seedlings of wild-type Col-0 and dj 1c T-DNA insertion mutants were fixed with $2.5 \%$ glutaraldehyde in $50 \mathrm{mM}$ sodium cacodylate $\mathrm{pH} 7.4$, under a vacuum for 3 hours, post-fixed in 1\% osmium tetroxide in $50 \mathrm{mM}$ sodium cacodylate $\mathrm{pH} 7.4$ for 2 hours, dehydrated in a graduated ethanol series, and embedded in Epon 812 (Electron Microscopic Sciences, Fort Washington, PA). Thin sections $(80-100 \mathrm{~nm})$ were stained with uranyl acetate and lead citrate and observed under a transmission electron microscope (Hitachi H7500-I) at University of Nebraska Lincoln's Microscopy Core Facility.

By examining organellar ultrastructure, well-developed mitochondria and nuclei were observed in cotyledons of wild-type Col-0 and $d j 1 c$ null mutants. However, the djlc plastids are smaller, deformed and devoid of thylakoid stacks and starch granules relative to wild type (Figure 2B). This was not unexpected given the albino and seedling lethal phenotype of the djlc null mutants (Figure 1) and the chloroplast targeting observed with GFP-tagged DJ1C (Figure 2A). Although dj1c mitochondria appear normal in these micrographs, further experiments will be used to verify whether wild-type sizes, numbers, and morphology are present.

References

[1] Y. Wei et al., PLoS Comp Biol 3 (2007) e10.

[2] L. Polanska et al., J Exp Bot 58 (2007) 637.

[3] The project described was supported by Grant Number 1P20RR17675 from the National Center for Research Resources (NCRR), a component of the National Institutes of Health (NIH). Its contents are solely the responsibility of the authors and do not necessarily represent the official views of NCRR or NIH. 

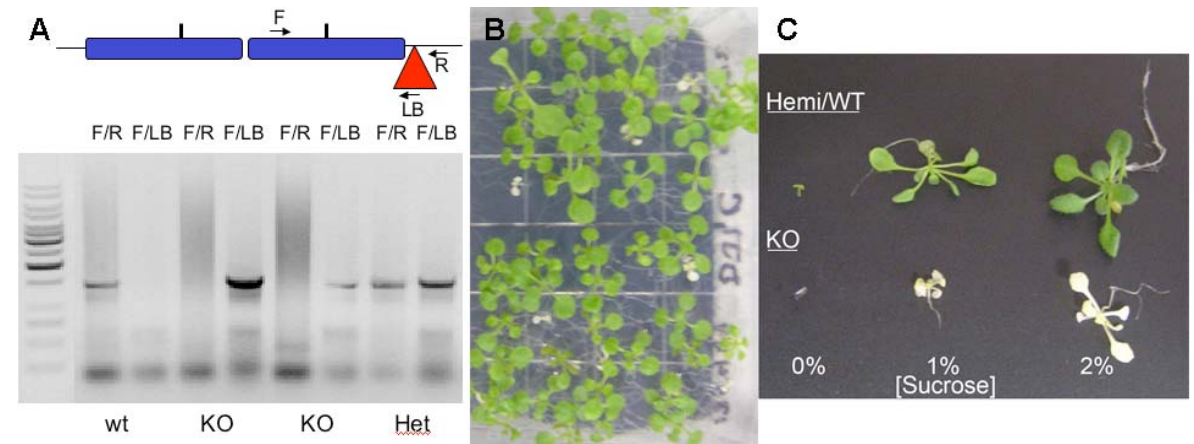

Figure 1. AtDJ1X

knockout mutants. (A)

PCR-based genotyping for

progeny of a plant

hemizygous for a T-DNA insertion in $A t D J 1 A$. PCR primers corresponding to the T-DNA and regions of the individual AtDJ1x genes flanking the T-DNA

insertion sites were used to genotype individual plants and identify null knockout mutants. Wild type (wt), homozygous knockout mutants (KO) and hemizygous T-DNA insertions (Het) were identified. (B) $D J I C$ is an essential gene, as a knockout mutation in $D J I C$ is seedling lethal. Seedlings from a plant hemizygous for a T-DNA insertion in $D J 1 C$. One quarter of the germinated seeds are small, albino seedlings that subsequently die, (segregating 3:1 for viable:albino; $\chi^{2}=0.128$, $\mathrm{n}=587$ ) as expected for a single, recessive mutation. (C) When transferred to fresh media containing higher concentrations of sucrose, dj $1 c$ null mutants grow beyond the cotyledon stage.

A
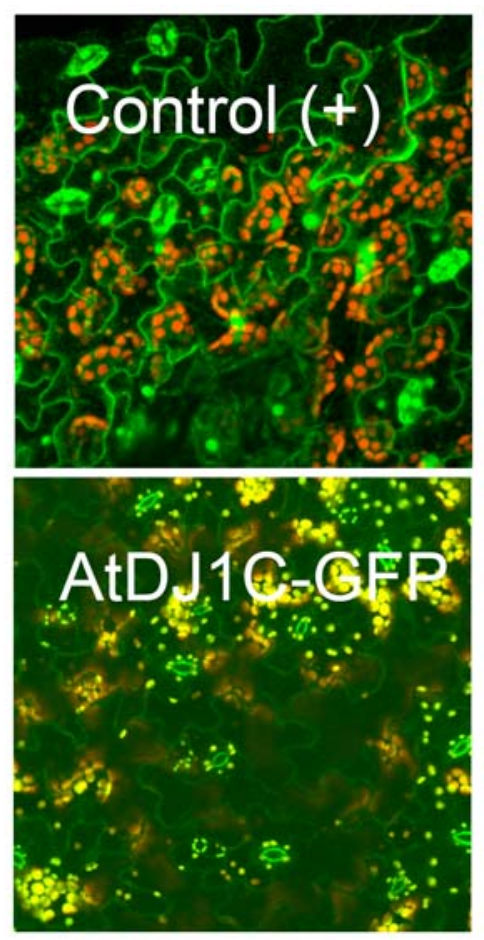

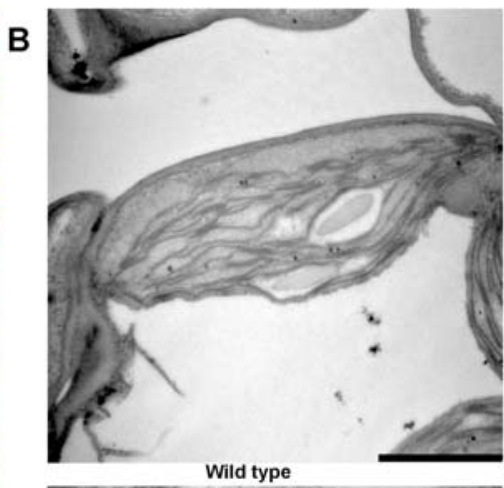

Wild type

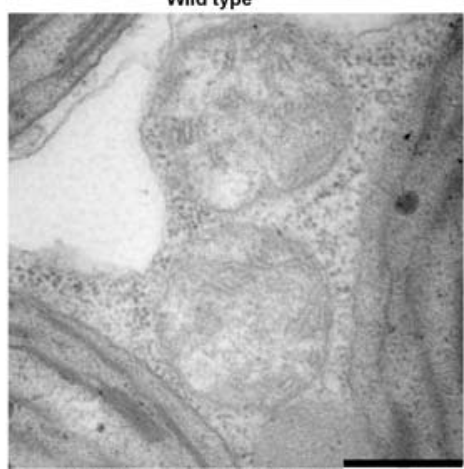

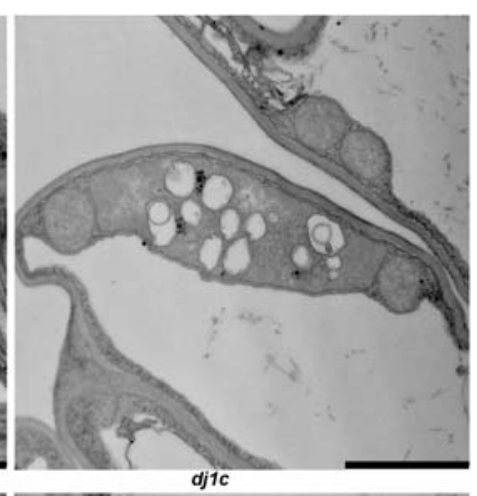

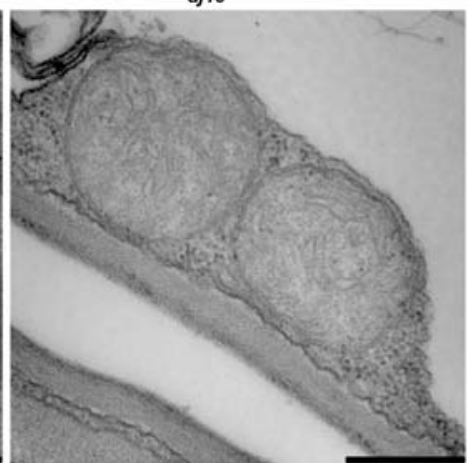

Figure 2. Subcellular localization of AtDJ1C and chloroplast ultrastructure in dj $\overline{1 c \text { mutants. }}$

(A) AtDJIC genomic DNA was cloned into the $\mathrm{pEGS}$ binary vector to produce in-frame C-terminal fusions to green fluorescent protein (GFP) driven by its native promoter. Subcellular localization of GFP in stably transformed $A$. thaliana was visualized by confocal microscopy at $60 \mathrm{X}$ magnification, and merged images from Z-series of leaf epidermal and mesophyll cells are shown. AtDJ1C::GFP was observed in small plastids. (B) Chloroplast ultrastructure is compromised in $d j 1 c$ cotyledons. Cotyledon tissues were prepared and analyzed as described above. Thin sections were stained and observed under a transmission electron microscope (Hitachi H7500-I). Black bars represent $2 \mu \mathrm{m}$ (top) or $0.5 \mu \mathrm{m}$ (bottom). 